\title{
Lo ganado y lo perdido después de dos décadas desde que América Latina fue declarada zona libre de poliomielitis
}

\author{
Losses and gains two decades after Latin America \\ was declared a poliomyelitis-free zone
}

$\mathrm{E}$ n las últimas décadas la producción historiográfica latinoamericana asiste a un proceso de renovación de la agenda de los historiadores en clave teórica, metodológica, pero también temática. La nueva historia de la salud y la enfermedad ha sido parte del mencionado proceso al ser uno de los sub campos historiográficos que mayor desarrollo y difusión ha logrado en los últimos tiempos.

Esto, en parte (solo en parte) resulta del hecho de ser las enfermedades, en su estado endémico o epidémico, un prisma de excelencia para analizar las políticas sanitarias, puesto que permiten ponderar el tipo de políticas públicas que modelaron los Estados, evaluando las formas de intervención que los mismos asumieron o escogieron para actuar frente a determinadas situaciones sanitarias. Pero como toda acción o inacción del aparato estatal genera reacciones sociales frente a los embates epidémicos, dichas reacciones asumen una intensidad distinta, donde las construcciones culturales en torno al proceso de salud enfermedad, a la muerte, a la cura, al valor de la vida - cobran una visibilidad diferente. Como también, adquiere una tonalidad llamativa el mundo de la medicina, puesto que una epidemia pone a prueba conocimientos, capacidades institucionales, perfiles profesionales, tecnologías etc. Pujas y acuerdos entre el poder político y la corporación médica es solo una parte del problema que acarrean las situaciones de crisis sanitarias, puesto que los desencuentros no solo se pueden vislumbrar entre el poder político y el poder médico, sino dentro de ambos poderes se abren gritas y se tejen nuevas alianzas que dan origen a intervenciones en el seno social. De allí entonces las riquezas y potencialidades de este enfoque.

Desde el punto de vista historiográfico, y dentro del campo de las enfermedades infectocontagiosas, las que se desarrollaron entre fines del siglo XIX y principios del XX han recibido gran atención por parte de los historiadores. Pero las epidemias del siglo XX, la centuria donde se inscribe el triunfo de la higiene, está en sus inicios. En este sentido, el siglo XX, que había comenzado caracterizado por un gran optimismo médico y social en torno al control de las infectocontagiosas, encendió sus signos de alarma frente a los embates de una enfermedad que sin piedad atacaba básicamente a los más pequeños. La infancia, estaba en peligro, justo en un momento cuando el mundo entero abogaba por la necesidad de establecer 
una protección integral mediante la consolidación de sus derechos, de su identidad. Una enfermedad parecía ensañarse con ellos: la poliomielitis. No eran los únicos, los adultos también padecían poliomielitis, pero el hecho de que los niños fueran afectados, despertó una serie de sensibilidades en torno a esta dolencia que pocas enfermedades estimularon.

Además, con ciertos particularismos, como el hecho de observarse desde finales del siglo XIX que la poliomielitis afectaba más a las poblaciones con cierto nivel socio económico, mientras que pasaba casi desapercibida en las poblaciones más pobres. El concepto de enfermedad y suciedad, que iba junto con el de enfermedad infecciosa, no parecía cumplirse en este caso. Puesto que, a mediados del siglo XX, la consolidación de la medicalización de las sociedades y del sanitarismo, en general, expresaban (para la mayoría de los países) una mejora higiénica y sanitaria, frente a este "triunfo de la higiene" aumentaba la frecuencia de la poliomielitis paralítica.

Por lo expuesto, y teniendo en cuenta que la propagación de la poliomielitis fue común tanto en Europa como en América Latina, entendemos que sería un gran aporte historiografico reunir un grupo de trabajos que ahonden en esta enfermedad de los tiempos modernos como forma de mostrar su estado en Iberoamérica, de fortalecer la recién formada Red de Estudios de la Polio y de la Síndrome Pospolimielitis en Iberoamérica, pero también como forma de mostrar los cambios e incorporaciones en la agenda de la Nueva Historia de la Enfermedad.

La reunión de trabajos sobre poliomielitis en Iberoamérica, desde el punto de vista historiográfico, constituye un gran desafío, cuyas potencialidades se centran en mirar de forma ampliada y comparada la poliomielitis y sus legados sociales e institucionales en un marco que involucra a sociedades y modelos de Estado diferentes, con generación de políticas públicas semejantes, con análogas respuestas de organización ciudadana. Este último aspecto intensifica la necesidad de un enfoque global con el fin de abocarnos a la búsqueda de interpretaciones integrales.

Los artículos compilados en este dossier son indicativos del interés de los investigadores iberoamericanos en la historia de la poliomielitis y de el sídrome pospolio y del grado de desarrollo de la temática. Además, el dossier pretende ser una instancia para reinstalar el debate sobre "la polio" y el síndrome pospolio en los ámbitos académicos, puesto que en 2014 se cumplieron 20 años, desde que América Latina fue declarada libre de la enfermedad.

Adriana Alvarez, Universidad Nacional de Mar del Plata, Conicet Dilene Raimundo do Nascimento, Casa de Oswaldo Cruz/Fiocruz 